\title{
Post-operative growth is different in various forms of pediatric Cushing's syndrome
}

\section{Dear Editor,}

Cushing's syndrome (CS) is a rare disease in children it is associated with weight gain and stunting of their linear growth (McArthur et al. 1980, Magiakou et al. 1994a, Stratakis 2012). In this study, we assessed growth in pediatric patients with CS after cure, caused by either adrenocorticotropic hormone (ACTH)-dependent Cushing's disease (CD) or a form of ACTH-independent CS, and patients with micronodular adrenal hyperplasia (MAH).

We reviewed medical records of patients who had successful transsphenoidal surgery or adrenalectomy at the NIH between the years of 2002 and 2012. A total of 18 children with $\mathrm{CD}(9 \mathrm{~F}$, mean age $12.2 \pm 3.0$ years) and 19 children with $\mathrm{MAH}$ (15 F, mean age $9.8 \pm 4.4$ years) were included. All patients were evaluated under the clinical protocol $97 \mathrm{CHO076}$ and $95 \mathrm{CHO059}$ that were approved by the NICHD Institutional Review Board. Informed consent was signed from the patients' parents. The diagnosis of CS was established as previously reported (Batista et al. 2007). Patients that were at Tanner stage 5 at the time of surgery were excluded from the analysis of annual growth velocity and insulin-like growth factor 1 (IGF1) $z$ scores.

The mean follow-up after surgery was $402 \pm 27$ days for the $\mathrm{CD}$ and $365 \pm 87$ days for the MAH patients $(P=0.09)$. No significant difference was found in terms of mean age (although CD patients were 2.4 years older), gender distribution, duration of symptoms, midnight cortisol levels, IGF1 $z$ score, and mean urinary free cortisol at the time of surgery. The demographics are presented in Table 1. The baseline height $(\mathrm{Ht}) z$ scores and BMI $z$ scores were not significantly different between the two groups $(P=0.85$ and $P=0.66$ respectively; Fig. $1 \mathrm{~A})$.

The mean $\mathrm{Ht} z$ score in $\mathrm{CD}$ before and after surgery was $-1.24 \pm 1.14$ and $-0.91 \pm 1.30$ respectively $(P=0.03)$. The mean $\mathrm{Ht} z$ score in MAH before and after surgery was $-1.33 \pm 1.64$ and $-0.62 \pm 1.37$ respectively $(P=0.0002$; Fig. 1B). The mean BMI $z$ score in $\mathrm{CD}$ before and after surgery was $2.07 \pm 0.62$ and $1.13 \pm 1.03$ respectively $(P<0.0001)$. The mean BMI $z$ score in MAH before and after surgery was $2.17 \pm 0.76$ and $1.14 \pm 0.84$ respectively $(P=0.0003$; Fig. 1C). The mean delta Ht $z$ score was $0.32 \pm$ 0.58 in the CDs vs $0.74 \pm 0.65$ in the MAH group, which was significantly better in MAH $(P=0.049)$. The mean delta BMI $z$ score was $-0.94 \pm 0.62$ in the CD group and $-1.04 \pm 1.0$ in the MAH group ( $P=0.74$; Fig. 1D).

We divided each group of patients into three categories, depending on their pubertal status: Tanner 1 , Tanner 2-3, and Tanner 4-5. The mean delta Ht $z$ scores in $\mathrm{CD}$ vs MAH were $0.51 \pm 0.35$ vs $1.03 \pm 0.78$ for Tanner 1 $(P=0.16) ; 0.08 \pm 0.66$ vs $0.83 \pm 0.40$ for Tanner $2 / 3$ $(P=0.024)$; and $0.07 \pm 0.30$ vs $-0.01 \pm 0.07$ for Tanner $4 / 5(P=0.59)$ (Fig. 1E).

There was a strong positive correlation between BMI $z$ score at surgery and the delta Ht $z$ score $(r=0.69$, $P=0.0012)$ in the MAH group but not in the CD group $(r=0.19, P=0.44)$. The correlation of the delta BMI $z$ score with delta $\mathrm{Ht} Z$ score also showed a strong correlation in the MAH group $(r=-0.67, P=0.002)$ but not in the CD group $(r=-0.18, P=0.48$ ) (Fig. 1F). Bone age $z$ score was $0.8 \pm 2$ and $0.6 \pm 1.4$ in the MAH and CD group respectively $(P=0.64)$, presented previously (Lodish et al. 2014).

For patients in Tanner categories 1-4 at surgery, the mean annual growth velocity was $10.47 \pm 2.69 \mathrm{~cm}$ in the MAH group vs $7.35 \pm 4.06 \mathrm{~cm}$ in the CD group $(P=0.017)$. The mean IGF1 $z$ score after surgery was $0.40 \pm 1.90$ vs $-0.77 \pm 1.33$ for the MAH and CD patients respectively $(P=0.050)$. When we excluded from the analysis the five MAH patients who are positive for a PRKAR1A mutation (patients that could have Carney complex, and thus increased IGF1 levels), we found a significant difference in the post-surgery IGF1 $z$ score, which was $0.98 \pm 2.03$ in the MAH group vs $-0.77 \pm 1.33$ in the $\mathrm{CD}$ group $(P=0.012)$. None of the patients in this analysis received growth hormone $(\mathrm{GH})$ or thyroid hormone treatment.

This is the first study to compare, after a curative surgical procedure, the growth of pediatric patients with

Published by Bioscientifica Ltd. 
Table 1 Clinical characteristics of CS patients at time of surgery, delta height $z$ scores and delta BMI $z$ scores before and after surgery, growth velocities and mutations in PRKARA1A

\begin{tabular}{|c|c|}
\hline Diagnosis & Age \\
\hline MAH1 & 9.9 \\
\hline MAH2 & 3.3 \\
\hline MAH3 & 13.8 \\
\hline MAH4 & 9.2 \\
\hline MAH5 & 6.4 \\
\hline MAH6 & 4.5 \\
\hline MAH7 & 16.4 \\
\hline MAH8 & 8.5 \\
\hline MAH9 & 8.6 \\
\hline MAH10 & 17.6 \\
\hline MAH11 & 3.8 \\
\hline MAH12 & 12 \\
\hline MAH13 & 10.7 \\
\hline MAH14 & 5.8 \\
\hline MAH15 & 10.8 \\
\hline MAH16 & 4.4 \\
\hline MAH17 & 15.9 \\
\hline MAH18 & 13.9 \\
\hline MAH19 & 10.6 \\
\hline CD1 & 15.1 \\
\hline CD2 & 9.2 \\
\hline CD3 & 16.4 \\
\hline CD4 & 13.2 \\
\hline CD5 & 14.3 \\
\hline CD6 & 10.9 \\
\hline CD7 & 15.7 \\
\hline CD8 & 13.4 \\
\hline CD9 & 16.7 \\
\hline CD10 & 11.1 \\
\hline CD11 & 6.8 \\
\hline CD12 & 12.2 \\
\hline CD13 & 10.3 \\
\hline CD14 & 10.8 \\
\hline CD15 & 10.4 \\
\hline CD16 & 10.8 \\
\hline CD17 & 15.3 \\
\hline CD18 & 7.1 \\
\hline
\end{tabular}

\begin{tabular}{|c|c|}
\hline Tanner & Gender \\
\hline Tanner 3 & Female \\
\hline Tanner 1 & Male \\
\hline Tanner 3 & $\begin{array}{l}\text { Male } \\
\text { Female }\end{array}$ \\
\hline Tanner 1 & Female \\
\hline Tanner 1 & Female \\
\hline Tanner 5 & Female \\
\hline Tanner 1 & Male \\
\hline Tanner 2 & Female \\
\hline Tanner 5 & Female \\
\hline Tanner 1 & Female \\
\hline Tanner 3 & Female \\
\hline Tanner 2 & Female \\
\hline Tanner 1 & Female \\
\hline Tanner 3 & Female \\
\hline Tanner 1 & Male \\
\hline Tanner 5 & Female \\
\hline Tanner 5 & Female \\
\hline Tanner 2 & Female \\
\hline Tanner 1 & Male \\
\hline Tanner 1 & Male \\
\hline Tanner 4 & Female \\
\hline Tanner 1 & Male \\
\hline Tanner 3 & Male \\
\hline Tanner 2 & Male \\
\hline Tanner 3 & Male \\
\hline Tanner 3 & Male \\
\hline Tanner 5 & Female \\
\hline Tanner 3 & Female \\
\hline Tanner 1 & Female \\
\hline Tanner 2 & $\begin{array}{l}\text { Female } \\
\text { Male }\end{array}$ \\
\hline Tanner 3 & Female \\
\hline Tanner 4 & Female \\
\hline \multirow{2}{*}{ Tanner 1} & Male \\
\hline & Female \\
\hline Tanner 1 & Female \\
\hline
\end{tabular}

\begin{tabular}{r}
\hline \\
\hline Dx height \\
\hline 1.166 \\
2.485 \\
0.243 \\
1.006 \\
0.792 \\
0.842 \\
0.055 \\
0.964 \\
1.372 \\
0.288 \\
1.551 \\
0.527 \\
1.098 \\
0.477 \\
0.625 \\
0.126 \\
-0.110 \\
0.019 \\
0.808 \\
0.550 \\
0.500 \\
0.113 \\
0.972 \\
0.272 \\
0.965 \\
-0.251 \\
0.315 \\
-0.239 \\
-0.241 \\
0.773 \\
-1.060 \\
0.416 \\
0.556 \\
0.349 \\
-0.043 \\
1.562 \\
0.337 \\
\end{tabular}

\begin{tabular}{r} 
\\
\hline Dx BMI \\
\hline-1.138 \\
-2.488 \\
0.604 \\
-1.298 \\
-0.744 \\
-2.965 \\
0.117 \\
-1.646 \\
-0.338 \\
-0.167 \\
-2.519 \\
-0.875 \\
-0.957 \\
-2.249 \\
-1.311 \\
0.341 \\
-0.013 \\
0.216 \\
-1.399 \\
-1.721 \\
-1.548 \\
-0.645 \\
-1.035 \\
-1.646 \\
-0.409 \\
0.041 \\
-1.947 \\
-0.565 \\
-0.514 \\
-1.243 \\
-0.216 \\
-0.497 \\
-0.472 \\
-0.758 \\
-1.900 \\
-0.483 \\
-1.446 \\
\end{tabular}

\begin{tabular}{|c|c|}
\hline $\begin{array}{c}\text { Growth velocity } \\
\text { (cm/year) }\end{array}$ & $\begin{array}{l}\text { PRKAR1A } \\
\text { mutation }\end{array}$ \\
\hline 12 & Yes \\
\hline 5.5 & No \\
\hline 9.1 & Yes \\
\hline 12.2 & No \\
\hline 10.9 & No \\
\hline 7.6 & No \\
\hline 12 & No \\
\hline 13.2 & No \\
\hline 12.5 & No \\
\hline 10.8 & No \\
\hline 14.3 & Yes \\
\hline 9.2 & No \\
\hline 11 & Yes \\
\hline 5.1 & Yes \\
\hline 11.6 & No \\
\hline 8.5 & \\
\hline 8.8 & \\
\hline 0.9 & \\
\hline 14.9 & \\
\hline 7.8 & \\
\hline 12.5 & \\
\hline 0.5 & \\
\hline 8.6 & \\
\hline 5.3 & \\
\hline 9.2 & \\
\hline 0 & \\
\hline 7.1 & \\
\hline 10.5 & \\
\hline 9.2 & \\
\hline 4.5 & \\
\hline 9.3 & \\
\hline 7.4 & \\
\hline
\end{tabular}

two forms of CS: CD and MAH. Our findings show that generally patients with MAH demonstrate better postoperative growth. There are several mechanisms that could explain the above observation.

First, the surgery can have a direct effect on the pituitary somatotrophs. In cases where the ACTH-secreting pituitary adenoma requires extensive surgical exploration, it is likely that the remaining pituitary cells will lose some of their function. Also, it is likely that the ACTH-producing tumor has a pressure effect on the somatotrophs that indirectly impairs the ability of the cells to produce GH.

Another reason is related to the direct adverse effects that the glucocorticoids have on the skeleton. It is possible that CD patients, who tend to be older, are exposed for a longer period of time to glucocorticoids, suffer vertebral fractures more frequently, and thus their skeleton and, hence their overall growth potential, is more affected. Moreover, patients with MAH can have cyclical forms of CS (Batista et al. 2007, Stratakis 2012), with hypercortisolism only intermittently present and an overall milder form of CS.

It is also possible that patients with $\mathrm{CD}$ are exposed to higher doses of glucocorticoids than what they need during their first 12 months of recovery. Although our group has shown that $75 \%$ of patients with CD should not require any hydrocortisone replacement by 14 months after surgery, and their glucocorticoids should be tapered starting after the first 6 months (and sometimes even sooner; Lodish et al. 2012), several patients are maintained on routine replacement for much longer, although the patients in the present study were all followed under our routine replacement doses, as described by Lodish et al. http://erc.endocrinology-journals.org DOI: 10.1530/ERC-14-0405 (c) 2014 Society for Endocrinology Printed in Great Britain 


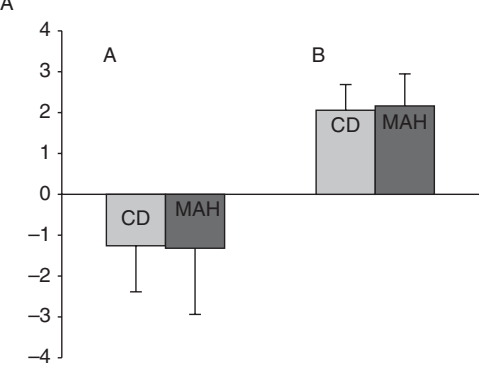

$\mathrm{D}$

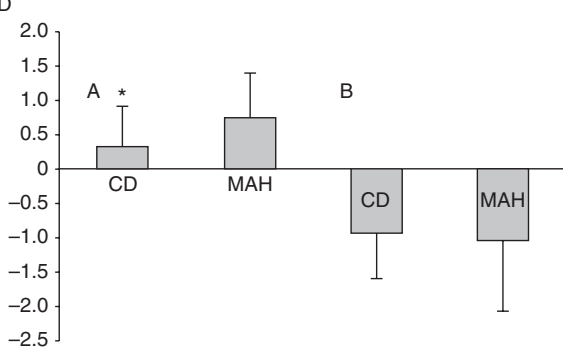

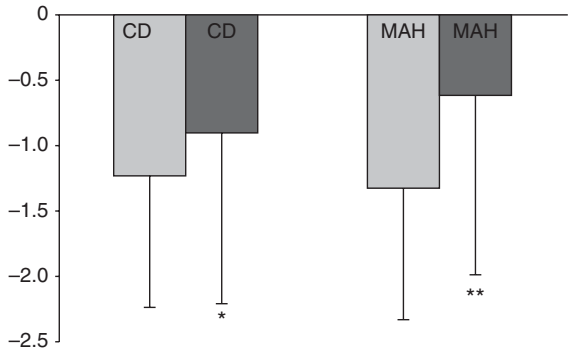

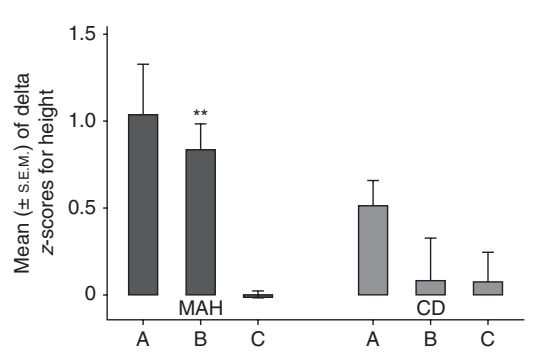

C
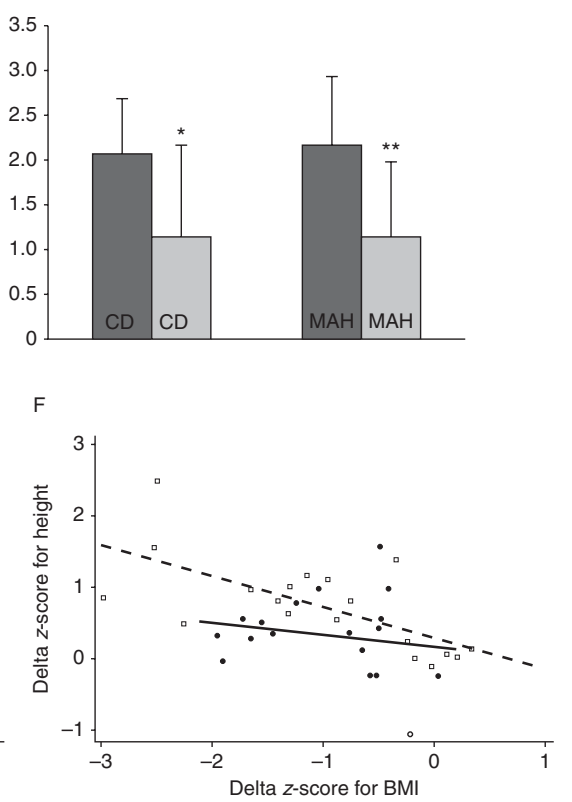

Figure 1

(A) Baseline height $z$ scores (left) and BMI $z$ scores (right) in CD and MAH at time of surgery. (B) Before and after surgery mean height $z$ score in $C D$ (left) and in $\mathrm{MAH}$ (right); $* P=0.03$ and $* * P=0.0002$. (C) Before and after surgery mean BMI $z$ score in CD (left) and in MAH (right); both groups improved significantly; ${ }^{*} P<0.0001$ and $* * P=0.0003$. (D) Mean delta height $z$ score in $\mathrm{CD}$ and MAH group (left) and mean delta BMI $z$ score in CD and MAH group

We have recently shown that patients with CD may, in some cases, have advanced bone age due to their ACTHstimulated adrenal androgen production and the latter's increased aromatization (Lodish et al. 2014), as well as their increased obesity and adiposity (London et al. 2014) and tendency to have higher insulin resistance (London et al. 2014) than those with MAH, especially those with PRKAR1A mutations (London et al. 2014). Thus, it is also possible that patients with $\mathrm{CD}$ would have decreased postoperative growth rate as a function of their advanced skeletal maturation compared with that of patients with MAH. Although this may be true in general, in the subgroup of patients included in this study, the degree of skeletal maturity at surgery was not most likely a factor, because the bone age $z$ scores were $0.8 \pm 2$ and $0.6 \pm 1.4$ in the MAH and CD groups respectively $(P=0.64)$.

In addition, the patients with the greatest improvement in their BMI values had better growth after cure. This is probably because the patients with severe obesity represent the most affected patients with CS, who also get the most benefit after cure. Whether the final adult $\mathrm{Ht}$ compared with their target $\mathrm{Ht}$ is also compromised remains to be seen. (right); $* * P=0.049$. (E) Delta height $z$ score between $\mathrm{CD}$ and MAH when compared for the same Tanner stage; $* P=0.024$ between Tanner II-III group of $C D$ and MAH. (F) Correlation of delta height $z$ score with delta $\mathrm{BMI} z$ score in $\mathrm{CD}$ and MAH. The open squares represent MAH, with the dashed least squares fitted line; the closed circles represent $C D$, with the solid least squares fitted line; correlation in MAH $r=-0.67$, with $P=0.02$.

Another possible mechanism to explain our findings may be the related to the fact that CS is associated with GH suppression (Frantz \& Rabkin 1964, Krieger \& Glick 1972, Magiakou et al. 1994b). Previous studies have shown that longer duration and higher degree of hypercortisolism lead to greater GH suppression (Frantz \& Rabkin 1964, Krieger \& Glick 1972). The GH secretion profile was abnormal even 1 year after cure of CS in a study done previously at NIH (Magiakou et al. 1994b). Some of our patients with $\mathrm{MAH}$ also have Carney complex and germline mutations in PRKAR1A gene (Stratakis et al. 2001). Carney complex can be associated with GH excess (Stratakis et al. 2001, Boikos \& Stratakis 2006, Bertherat et al. 2009). Clinically apparent acromegaly in Carney complex occurs mostly in young adulthood (Stratakis et al. 2001, Boikos \& Stratakis 2006, Bertherat et al. 2009), but it is possible that abnormal GH secretion exists in early childhood (Boikos \& Stratakis 2006) and this is manifested in our patients with MAH as an earlier recovery of GH secretion than one would expect. However, even when we excluded the subset of patients with PRKAR1A mutations, the MAH patients still had higher IGF1 $z$ scores after cure when compared with $\mathrm{CD}$ patients.

Published by Bioscientifica Ltd. 
Finally, this study demonstrated that patients with MAH grow significantly better after surgery, even when compared with a group of CD patients of the same Tanner stage at the time of surgery (Dupuis et al. 2007). A limitation of our study is that we do not have GH secretion profiles after surgery and adult final $\mathrm{Ht}$ in these patients.

In conclusion, there are important messages from these clinical observations: patients with MAH are less likely to need GH therapy after surgery for their CS. On the other hand, physicians should monitor patients with CD very closely and have a low threshold for considering treatment with GH to improve their final adult Ht. Finally, every effort for improvement in BMI with lifestyle modification could potentially improve growth of children with CS after they are cured.

\section{Evgenia Gourgari ${ }^{1,2,3}$ \\ Maya Lodish ${ }^{12}$ \\ Meg Keil ${ }^{1,2}$ \\ Robert Wesley ${ }^{4}$ \\ Suvimol Hill ${ }^{5}$ \\ Paraskevi Xekouki ${ }^{1}$ \\ Charalampos Lyssikatos ${ }^{1}$ \\ Elena Belyavskaya ${ }^{1}$ \\ Sierra Maria De La Luz ${ }^{1}$ \\ Constantine A Stratakis ${ }^{1,2}$}

${ }^{1}$ Section on Endocrinology and Genetics, Program on Developmental Endocrinology and Genetics (PDEGEN)

Bethesda, Maryland, USA

${ }^{2}$ Pediatric Endocrinology Inter-Institute Training Program Eunice Kennedy Shriver National Institute of Child Health and Human Development (NICHD), National Institutes of Health (NIH), Bethesda, Maryland 20892, USA

${ }^{3}$ Department of Pediatric Endocrinology, Georgetown University School of Medicine, 3800 Reservoir Road Washington, District of Columbia 20007, USA

${ }^{4}$ Biostatistics and Clinical Epidemiology Service, National Institutes of Health Clinical Center, Bethesda Maryland 20982, USA

${ }^{5}$ Department of Radiology, National Institutes of Health Clinical Center Bethesda, Maryland 20892, USA

(Correspondence should be addressed to E Gourgari, Division of Pediatric Endocrinology Georgetown University Hospital, 4200 Wisconsin Avenue, N.W, 4th Floor, Washington DC 20016, USA;

Email: evgenia.gourgari@gunet.georgetown.edu)
Declaration of interest

The authors declare that there is no conflict of interest that could be perceived as prejudicing the impartiality of the research reported.

Funding

This study was supported by the NIH Intramural Research Program of the Eunice Kennedy Shriver National Institute of Child Health and Human Development (NICHD). Clinical Trial Registration Number, NCT00001595.

\section{Author contribution statement}

E Gourgari performed most of the data collection described in the manuscript and prepared the manuscript. $M$ Lodish is currently the principal investigator for the clinical protocols. M Keil, C Lyssikatos, and E Belyavskaya participated in the clinical care of the patients. $R$ Wesley did the statistical analysis. $\mathrm{S}$ Hill was responsible for the reading and interpretation of bone age films of the patients. S M De La Luz and P Xekouki participated in the genetic analysis of the patients. C A Stratakis was the principal investigator of the clinical protocol until recently, saw all the patients, and his NIH Intramural Grant provided all of the funding for this project; he also supervised the presentation of results, design of figures, and assisted in writing this manuscript.

\section{References}

Batista DL, Riar J, Keil M \& Stratakis CA 2007 Diagnostic tests for children who are referred for the investigation of Cushing syndrome. Pediatrics 120 e575-e586. (doi:10.1542/peds.2006-2402)

Bertherat J, Horvath A, Groussin L, Grabar S, Boikos S, Cazabat L, Libe R, Rene-Corail F, Stergiopoulos S, Bourdeau I et al. 2009 Mutations in regulatory subunit type $1 \mathrm{~A}$ of cyclic adenosine $5^{\prime}$-monophosphatedependent protein kinase (PRKAR1A): phenotype analysis in 353 patients and 80 different genotypes. Journal of Clinical Endocrinology and Metabolism 94 2085-2091. (doi:10.1210/jc.2008-2333)

Boikos SA \& Stratakis CA 2006 Pituitary pathology in patients with Carney complex: growth-hormone producing hyperplasia or tumors and their association with other abnormalities. Pituitary 9 203-209. (doi:10.1007/ s11102-006-0265-2)

Dupuis CC, Storr HL, Perry LA, Ho JT, Ahmed L, Ong KK, Dunger DB, Monson JP, Grossman AB, Besser GM et al. 2007 Abnormal puberty in paediatric Cushing's disease: relationship with adrenal androgen, sex hormone binding globulin and gonadotrophin concentrations. Clinical Endocrinology 66 838-843. (doi:10.1111/j.1365-2265.2007. 02822.x)

Frantz AG \& Rabkin MT 1964 Human growth hormone. Clinical measurement, response to hypoglycemia and suppression by corticosteroids. New England Journal of Medicine 271 1375-1381. (doi:10.1056/ NEJM196412312712701)

Krieger DT \& Glick SM 1972 Growth hormone and cortisol responsiveness in Cushing's syndrome. Relation to a possible central nervous system etiology. American Journal of Medicine 52 25-40. (doi:10.1016/00029343(72)90005-8)

Lodish M, Dunn SV, Sinaii N, Keil MF \& Stratakis CA 2012 Recovery of the hypothalamic-pituitary-adrenal axis in children and adolescents after surgical cure of Cushing's disease. Journal of Clinical Endocrinology and Metabolism 97 1483-1491. (doi:10.1210/jc.2011-2325)

Lodish MB, Gourgari E, Sinaii N, Hill S, Libuit L, Mastroyannis S, Keil M, Batista DL \& Stratakis CA 2014 Skeletal maturation in children with Cushing syndrome is not consistently delayed: the role of http://erc.endocrinology-journals.org DOI: 10.1530/ERC-14-0405
(C) 2014 Society for Endocrinology Printed in Great Britain 
corticotropin, obesity, and steroid hormones, and the effect of surgical cure. Journal of Pediatrics 164 801-806. (doi:10.1016/j.jpeds. 2013.11.065)

London E, Rothenbuhler A, Lodish M, Gourgari E, Keil M, Lyssikatos C, de la Luz Sierra M, Patronas N, Nesterova M \& Stratakis CA 2014 Differences in adiposity in Cushing syndrome caused by PRKAR1A mutations: clues for the role of cyclic AMP signaling in obesity and diagnostic implications. Journal of Clinical Endocrinology and Metabolism 99 E303-E310. (doi:10.1210/jc.2013-1956)

Magiakou MA, Mastorakos G, Oldfield EH, Gomez MT, Doppman JL, Cutler GB Jr, Nieman LK \& Chrousos GP 1994a Cushing's syndrome in children and adolescents. Presentation, diagnosis, and therapy. New England Journal of Medicine 331 629-636. (doi:10.1056/ NEJM199409083311002)
Magiakou MA, Mastorakos G, Gomez MT, Rose SR \& Chrousos GP $1994 b$ Suppressed spontaneous and stimulated growth hormone secretion in patients with Cushing's disease before and after surgical cure. Journal of Clinical Endocrinology and Metabolism 78 131-137.

McArthur RG, Hayles AB \& Salassa RM 1980 Growth retardation in Cushing disease. Journal of Pediatrics 96 783-784. (doi:10.1016/S00223476(80)80782-7)

Stratakis CA 2012 Cushing syndrome in pediatrics. Endocrinology and Metabolism Clinics of North America 41 793-803. (doi:10.1016/j.ecl. 2012.08.002)

Stratakis CA, Kirschner LS \& Carney JA 2001 Clinical and molecular features of the Carney complex: diagnostic criteria and recommendations for patient evaluation. Journal of Clinical Endocrinology and Metabolism 86 4041-4046. (doi:10.1210/jcem.86.9.7903)

Received in final form 19 September 2014

Accepted 23 September 2014

Made available online as an Accepted Preprint

25 September 2014
Published by Bioscientifica Ltd. 